\title{
Rediscovery of a forgotten disease: Hereditary Angioedema
}

\author{
Okan Gülbahar ${ }^{1} \oplus$, Anastasios E. Germenis ${ }^{2}$
}

${ }^{1}$ Division of Immunology-Allergy, Department of Internal Medicine, Ege University School of Medicine, İzmir, Turkey

${ }^{2}$ Department of Immunology and Histocompatibility, School of Medicine, University of Thessaly, Larissa, Greece

\begin{abstract}
The Anatomy of a Trajectory
Angioedema is an ambiguous term. It defines a clinical phenotype characterized by localized and self-limiting edema of the subcutaneous and submucosal tissue caused by a temporary release of the vasoactive mediators and the resulting increase of the vascular permeability. Most often, angioedema coexists with wheals, either during anaphylactic reactions or in patients with chronic urticaria. Less frequently, however, this phenotype appears repeatedly in the absence of significant wheals, and then the term angioedema signifies a distinct disease.
\end{abstract}

The current classification and nomenclature of angioedema without wheals ${ }^{1,2}$ have evolved over the last centuries with many detours and problems complicating the understanding of this interesting condition. ${ }^{3,4}$ First, many different names had been used for its description because of changes in the understanding of its pathogenesis and the underlying causes. Second, but most importantly, because it is well known nowadays, angioedema without wheals represents a heterogeneous group of clinically indistinguishable diseases of genetic or acquired etiology. Interestingly, evidence accumulating during the last decades indicates that different endotypes might underlie the various hereditary or acquired forms of angioedema. Finally, the genetic basis of many hereditary types of angioedema remains undetermined. It is therefore characterized as unknown, whereas the etiology of some acquired forms is still undetectable, imposing their definition as idiopathic.

Starting the story, Anna Barnett began her 1948 article entitled "Hereditary Angioneurotic Edema: A Remarkable Family History"s with the following description of a case of recurrent angioedema from a book published by Franz Anton Mai in 1777:

"A worthy gentleman had attained his 62nd year, awoke one morning with a remarkably puffy face. The lips and eyelids were unbelievably swollen as if he had been stung by a bee or a wasp. The swelling was lymphatic, without noticeable inflammation, and entirely without pain, burning, or itching. The swelling had complete$l y$ disappeared by afternoon; it had left the face and descended to the scrotum. The patient felt the arrival of the new swelling as a brief, sharp sting... whole scrotum was swollen...like a monstrous hydrocele... Inside of five or six hours, the malevolent trouble disappeared and flew to the tongue. The tongue could no longer find room in the throat. It swelled out through the lips and filled all who saw it with pity and fear... The swelling remained stubborn, changing its place every day. Now it was the left, now the right ear, now both; now the eyelids, or the forehead, now the arm. This remarkable and dangerous evil, might perhaps have killed the patient in spite of his sound heart. A consultant suggested that the cause of the frequent relapses might be found in the digestive tract."

Apart from a case of urticaria and angioedema associated with egg allergy reported by Marcello Donati, ${ }^{6}$ this patient can be considered the first case of recurrent angioedema to be documented in modern medicine with fairly well-described clinical features. ${ }^{7} \mathrm{Al}-$ though there is no known publication from the 17th century, in 1967, Arnoldsson et al. ${ }^{8}$ were able to access the records of "hereditary periodic edema" dating back to the 17 th-century uninterrupted church records of a family with angioedema. Robert James Graves, whom a form of hyperthyroidism (Graves' disease) was named after, described another case of episodic angioedema in 1843. ${ }^{9}$ In 1876, John Laws Milton named this situation as giant urticaria in a woman with swelling so extensive that it completely covered both of her eyes. ${ }^{10}$ Eugen Dinkelacker, a student of Heinrich Ireanus Quincke, presented his doctoral thesis examining 14 cases of angioedema described as having acute-onset and well-defined swelling. In his dissertation, he cited 12 previous publications as references. Immediately afterward, in 1882, Quincke published a summary of that study but did not mention the earlier papers. ${ }^{11}$ From that date on, the disease began to be referred to as Quincke's edema. In later case reports, the term angioneurotic edema started to be used to claim that the condition was related to neurotic effects. Paul Strübing first proposed this name in $1885 .{ }^{12}$ In 1888, Sir William Osler's article entitled "Hereditary Angioneurotic Edema" was published, highlighting the hereditary nature of the disease. ${ }^{13}$ In this article, Osler describes a 24-year-old woman who had experienced recurrent episodes of swelling involving the extremities, hips, genitals, and pharynx since childhood. He stated that 28 other family members spanning 5 generations had the same symptoms and that 2 had died owing to asphyxiation. Osler emphasized 3

Address for Correspondence: Okan Gülbahar, Division of Immunology-Allergy, Department of Internal Medicine, Ege University School of Medicine, İzmir, Turkey

e-mail: okan.gulbahar@ege.edu.tr

Received: November 4, 2020 Accepted: December 13, 2020 • DOI: 10.5152/balkanmedj.2021.20030

Available at www.balkanmedicaljournal.org

ORCID iDs of the authors: O.G. 0000-0002-5341-9070; A.E.G. 0000-0002-3315-6947.

Cite this article as:

Gülbahar O, Germenis AE. Rediscovery of a forgotten disease: Hereditary Angioedema. Balkan Med J. 2021;38(2):68-72.

Copyright@Author(s) - Available online at http://balkanmedicaljournal.org/ 
crucial features of the disease: local swelling of various parts of the body, frequent gastrointestinal involvement, and a marked hereditary tendency. In 1917, Crowder and Crowder examined the inheritance patterns of a family over 5 generations and reported that this disease was consistent with an autosomal dominant inheritance model. ${ }^{14}$

Although case series continued to be published in subsequent years, no significant progress in clarifying the disease's pathogenesis was achieved for quite some time. After World War II, studies in immunology and hematology began to elucidate the enzymatic interactions between the complement cascade and intrinsic coagulation components and nonhistamine-induced serum permeability factors. Within a decade, a series of advances, such as the discovery of serum permeability factor, pathways for Hageman factor activation, and the functions of the complement serine protease and its inhibitor, were reported in quick succession. In 1961, Irwin H. Lepow and his group ${ }^{15}$ discovered the enzyme that inhibits the first component of the complement system $(\mathrm{C} 1)$ and called it C1-esterase inhibitor (the name used for $\mathrm{C} 1$ inhibitor [C1-INH] at that time), marking a new milestone. Following all of these studies, Landerman et al. ${ }^{16}$ focused on the similarities and differences between allergic and nonallergic types and the hereditary and nonhereditary types of angioedema. This revealed clinical clues that would assist clinicians. Nathaniel Landerman, Virginia Donaldson, and Oscar Ratnoff demonstrated a permeability factor and a factor that inhibits kallikrein in these patients. This finding was important because it was the first to point out kallikrein's role, a potent vascular permeability factor from the contact system, in hereditary angioedema (HAE).

Within a short time, Donaldson and Evans demonstrated that the early complement enzyme $\mathrm{C} 1$ esterase is an essential mediator of vascular permeability in HAE on the basis of the biochemical absence of C1-esterase inhibitor in patients with HAE. ${ }^{17,18}$ The researchers showed that a patient, previously known to have kallikrein inhibitor deficiency, also lacked C1 inhibitor and speculated on the basis of this finding that $\mathrm{C} 1$ inhibitor and kallikrein inhibitor were closely associated. A few years later, Donaldson et al. ${ }^{16}$ showed that the permeability-enhancing factor in the plasma of patients with HAE also had kinin-like effects. ${ }^{17}$ Although this kinin was similar to kallidin and bradykinin, its proteolysis by trypsin was a distinguishing feature.

In 1965, a few years after the biochemical defect in HAE was demonstrated, Rosen et al. ${ }^{19}$ reported a family with normal serum C1-INH levels but impaired inhibition. As other similar cases were reported, 2 different types of HAE were recognized: HAE type I (in which there is low or no antigen and low or no estereolytic activity) and HAE type II (in which antigen levels are normal or even high, but functional activity is substantially reduced). Those were the golden years when we came to understand how the disease develops. Schapira et al. showed that plasma prekallikrein and high-molecular-weight kininogen were consumed during HAE attacks. ${ }^{20}$ Allen Kaplan and his group demonstrated the relationship between the complement and contact systems by showing that FXII activation by prekallikrein further activated complement component $1 \mathrm{r}$ and prekallikrein. ${ }^{21}$ After the purification of $\mathrm{C} 1$ INH, amino acid sequencing studies were also started. In 1986, Bock et al. ${ }^{22}$ published the peptide and amino acid sequences of the entire molecule. A comparison of the amino acid and complementary DNA sequences revealed that $\mathrm{C} 1-\mathrm{INH}$ is a member of the large serine protease inhibitor (SERPING1) family. Theriault et al. ${ }^{23}$ used in situ hybridization to map the C1-INH gene to chromosome 11 at the q11-q13.1 position, and Janson et al. mapped it to the 11q12-q13.1 position. However, despite these developments in determining HAE pathophysiology, it was not until 1998, 110 years after the disease was first described, that Nussburger et al. ${ }^{24}$ were able to show that bradykinin was the mediator that caused increased vascular permeability as a result of contact system activation.

\section{Deciphering the Complexity}

At the end of the last century, efforts toward understanding angioedema without wheals had concluded that it was almost equivalent to the hereditary deficiency of C1-INH. Only a few cases of acquired deficiency of C1-INH had been described after the identification by Caldwell et al. ${ }^{25}$ of a patient with angioedema in whom the C1-INH deficiency was not hereditary but related to concomitant lymphosarcoma. Similarly, angiotensin-converting enzyme inhibitors (ACEis), which encompass angioedema as a side effect, were invented just in 1980, and owing to the low incidence of this side effect $(<1 \%$ of treated subjects), the acquired form of angioedema related to ACEi had not yet attracted the attention of the researchers. ${ }^{26}$ Nevertheless, HAE due to C1-INH deficiency (C1INH-HAE) had served as nature's experiment that taught us much of what we know about the plasma contact system. ${ }^{27}$ In parallel, various regulatory incentives in both the European Union countries and the United States that stimulated the research on rare diseases lead to the development of an abundance of medicinal products for HAE, which may not exist for any other rare disease. ${ }^{28}$

The event that thereafter set the pace of angioedema research was the description in 2000 by 2 independent groups of families with $\mathrm{HAE}$ in which the affected individuals had entirely normal $\mathrm{C} 1$ $\mathrm{INH}$ level and function (HAE with normal C1-INH [nC1-INHHAE]). ${ }^{29,30}$ After that, indirect evidence was accumulated, indicating that this form of HAE may also be a bradykinin-mediated disease. At the same time, in 2006, Dewald and Bork ${ }^{31}$ discovered that some families with nC1-INH-HAE had mutations in exon 9 of the FXII gene, which encodes for the FXII coagulation factor (Hageman factor). However, only a small proportion of nC1-INHHAE cases (up to $25 \%$ in Europe) were finally attributable to FXII mutations. ${ }^{32}$ During the next years, the advent of high-throughput next-generation sequencing (NGS) technologies accelerated the coverage of the missing part of $\mathrm{nC} 1-\mathrm{INH}-\mathrm{HAE}$ genetics, and $\mathrm{nC} 1$ INH-HAE was further fragmented by the discovery of 4 novel target genes (ANGPT1, PLG, KNG1, and $M Y O F)^{33}$, the list of which is expected to grow up during the forthcoming years. ${ }^{34}$ The most important contribution of these discoveries was the broadening of our concept of HAE pathophysiology from an exclusive focus on the contact system to the inclusion of the vascular bed itself. ${ }^{35} \mathrm{El}-$ egant studies provide convincing evidence that HAE is a model of the so-named paroxysmal permeability disorders characterized by 
an impairment of the endothelial barrier function. ${ }^{36}$ However, the new players (such as ANGPT1 and MYOF), their relationship with bradykinin signaling, and the new gene variants' precise pathogenic mechanisms remain to be elucidated.

The comprehensive implementation of NGS technologies also accelerated the SERPING1 gene study uncovering variants causal for C1-INH-HAE that were undetectable by conventional genotyping. Thus, up till now, a total of 750 distinct SERPING1 variants related to $\mathrm{C} 1-\mathrm{INH}-\mathrm{HAE}$ have been reported, among which are 2 novel pathogenic deep intronic variants. ${ }^{37-39}$ Studies of mutated C1-INH have shed light on many unresolved issues of the disease, such as the old finding that most patients with C1-INH-HAE type I present $\mathrm{C} 1-\mathrm{INH}$ plasma despite the heterozygotes levels often being around $20 \%$ of the normal. ${ }^{40}$ Very recently, Haslund et al. ${ }^{41}$ have shown that in a subset of patients with C1-INH-HAE, mutated C1INH acts on wild-type $\mathrm{C} 1$-INH in a dominant-negative manner and forms intracellular $\mathrm{C} 1-\mathrm{INH}$ aggregates, which lead to a reduction in the levels of secreted functional C1-INH. A problem arising from the use of NGS in the diagnostic context is the confirmation of the pathogenicity of SERPING1 variants that sometimes is very difficult to be confirmed by family segregation or functional studies. Therefore, it is imperative for those involved in the genetic diagnosis of HAE to report SERPING1 variants and the data supporting their pathogenicity in public databases, such as ClinVar and others.

Another area of particular progress during the last decade was the development of biochemical biomarkers for HAE diagnosis and prognosis. At least 4 assays for the diagnosis of HAE are ready to enter the market, namely the cleavage of high-molecular-weight kininogen in patient's plasma ${ }^{42}$; the spontaneous amidase activity ${ }^{43}$; the threshold-stimulated kallikrein assay ${ }^{44}$; and, most recently, the fragmentation patterns of serum glycoprotein $120 .{ }^{45}$ Great efforts toward discovering more specific biochemical biomarkers for HAE are based on the continuously accumulating knowledge of the contact system biology. ${ }^{46}$ However, despite the urgent need for biomarkers to accompany clinical trials and enable personalized medicine, a striking discrepancy exists between the effort directed toward discovering biochemical biomarkers for HAE and the number of them with a promising applicability clinical utility.

\section{The Dark Side}

The enormous progress made toward understanding the pathophysiology of angioedema without wheals uncovered at the same time a series of issues necessitating further clarification. The main problem in the management of angioedema is that despite the rich armamentarium of therapeutic agents, a significant proportion of patients with HAE continues to be treated on a trial-and-error basis owing to the absence of definite indications. ${ }^{47}$ Thus, whereas healthcare costs of patients with angioedema continuously escalate, many patients still report poor disease control, followed by substantial morbidity, psychological stress, decreased productivity, and low quality of life. ${ }^{48}$ This is a direct consequence of the fact that no convincing interpretation has been provided for the extensive clinical variability of the disease. As it is well known, features of the disease, such as the age of disease onset, frequency and triggers of attacks, severity and localization of edema, prodromal signs and symptoms, and the need for long-term treatment, vary broadly even among members of the same family sharing the same mutation. ${ }^{49,50}$

Several factors have been considered responsible for the variable penetrance and expressivity of HAE. Environmental factors had been very early blamed ${ }^{51}$, but strong evidence of their effect on the stability and the functional activity of some $\mathrm{C} 1-\mathrm{INH}$ mutants has been provided only recently. ${ }^{52}$ Another explanation of HAE expression variability is the effect of genes called modifier genes, which can change the phenotypic outcome of the primary mutation in the causal gene. ${ }^{53}$ The functional promoter polymorphism F12-46C/T and the functional polymorphism KLKB1-428G/A have been shown to be associated with a significant delay in the onset of $\mathrm{C} 1$ INH-HAE and with a significantly lower probability of the need for long-term prophylaxis. ${ }^{54,55}$ Moreover, the F12-46C/T polymorphism's TT genotype has been significantly associated with a 25-fold lower risk of developing symptoms of C1-INH-HAE. ${ }^{56}$ The lower translation efficacy of the F12-46C/T polymorphism results in decreased FXII plasma levels and, given the importance of FXII in the bradykinin-forming cascade, justifies its protective role in HAE. However, mice deficient in FXII still generate 50\% bradykinin under baseline conditions, ${ }^{57}$ a fact signifying that there are FXII-independent factors to generate bradykinin ${ }^{58,59}$ that deserve attention as clinical disease modifiers in HAE. For example, aminopeptidase-P activity, which inactivates bradykinin, has been correlated inversely with disease severity in C1-INH-HAE. ${ }^{60}$ Generally, enzymes that regulate the breakdown of bradykinin are suspected disease modifiers. ${ }^{61}$

Notwithstanding the knowledge achieved about the plasma contact or kallikrein-kinin system and the role of bradykinin in C1-INHHAE, a gap still remains regarding understanding its clinical phenotype on a molecular level. Even though there is an uncontrolled production of bradykinin by plasma contact system and an increase of bradykinin in the bloodstream during HAE attacks, general vascular leakage or edema is not an accompanying symptom, as was expected. ${ }^{62-65}$ Instead, HAE attacks are characterized by self-limiting swelling restricted to a particular location of the body. A total of 2 opposing models are attempting to provide a solution to this problem.

The first of them assumes a systemic, fluid-phase activation of the contact system and the interaction of generated bradykinin and its byproducts with locally expressed endothelial receptors (B1R) rather than with receptors continuously expressed by the endothelium throughout the vasculature (B2R). ${ }^{59,66}$ More specifically, this model proposes that bradykinin is not directly responsible for edema formation but, along with other inflammatory stimuli (e.g., cytokines), functions only as a stimulator of B1R on the vascular endothelium. Swelling results from the prolonged vasodilatation induced and thereafter, by the interaction of upregulated B1R with des-arg9-bradykinin, a breakdown product of bradykinin. This model explains why swellings can occur at multiple sites during the same HAE attack, ${ }^{67}$ possibly preceded by muscle aches, rash, and fatigue. ${ }^{68,69}$ On the other side, the absence of hypotension during HAE attacks and, more importantly, the efficacy of the se- 
lective B2R antagonist icatibant in C1-INH-HAE argue against this model.

Alternatively, an excessive bradykinin production by the swollen tissues per se is proposed, suggesting that swelling HAE attacks are localized events rather than a generalized phenomenon. ${ }^{51,59}$ According to this model, various receptors (uPAR, gclqR, and others) recruit and activate factors of the contact system in the vascular endothelium as a response to (yet incompletely recognized) danger signals from the underlying tissue. ${ }^{70}$ This facilitates the enzymatic crosstalk and the generation of bradykinin, and when it is insufficiently controlled, such as in HAE, it may result in swelling. Indeed, it is well known that viral and bacterial infections activate the contact system and that the resulting bradykinin generation and increase of endothelial cell permeability can be blocked by an FXII inhibitor or B2R antagonist. ${ }^{71,72}$ Moreover, recent evidence indicates that the vascular endothelial growth factor could trigger local stimulation of the endothelial cells and bradykinin production. ${ }^{73,74}$

In conclusion, significant advances made during the last decade toward understanding HAE pathogenesis uncovered the disease's fundamental biological aspects that require further elucidation to reconcile with clinical data. Such an attempt would be proved valuable for the management of HAE and more common disorders where relevant mechanisms contribute to their pathogenesis.

Author Contributions: Concept - O.G., A.E.G.; Design - O.G., A.E.G.; Supervision O.G., A.E.G.; Literature Review - O.G., A.E.G.; Writing - O.G., A.E.G.; Critical Review - O.G., A.E.G.

Conflict of Interest: The authors have no conflicts of interest to declare.

Funding: The authors declared that this study has received no financial support.

\section{REFERENCES}

1. Cicardi M, Aberer W, Banerji A, et. al. Classification, diagnosis, and approach to treatment for angioedema: consensus report from the Hereditary Angioedema International Working Group. Allergy. 2014;69(5):602-616. [Crossref]

2. Proper SP, Lavery WJ, Bernstein JA. Definition and classification of hereditary angioedema. Allergy Asthma Proc. 2020;41(Soppl 1):S03-S07. [Crossref]

3. Reshef A, Kidon M, Leibovich I. The story of angioedema: from Quincke to bradykinin. Clin Rev Allergy Immunol. 2016;51:121-139. [Crossref]

4. Maurer M. Urticaria and angioedema. Chem Immunol Allergy. 2014;100:101-104. [Crossref]

5. Barnett AF. Hereditary angioneurotic edema: a remarkable family history. Calif Med. 1948;69(5):376-380

6. Donati M: De medica historia mirabile. Mantua, Osana, 1586, vol 7, chapt 3, p 304.

7. Mai FA. Stolpertus, ein junger Arzt am Krankenbette. Schwann \& Götz, Mannheim, $1777,1807$.

8. Arnoldsson H, Belin L, Hallberg L, Helander E, Lindholm B, Westling H. Hereditary periodic oedema. Acta Med Scand. 1967;181(1):115-124. [Crossref]

9. Graves R. Clinical lectures on the practice of medicine. In: Major MH (ed) Classic descriptions of disease, 3rd edn. Charles C. Thomas, Springfield, 1843, pp 623-624.

10. Milton JL. On giant urticaria. Edinb Med J. 1876;22:513-526. [Crossref]

11. Quincke H. Uber akutes umschriebenes Hautoedem. Mschr Prakt Dermatol. 1882;1:160-169.

12. Strübing P. Uber acutes (angioneurotisches) Odem. Zeitschr F Klin Med. 1885;9:381.

13. Osler W. Hereditary angio-neurotic oedema. Am J Med Sci. 1888;95:362. [Crossref]

14. Crowder JR, Crowder TR. Five generations of angioneurotic edema. Arch Int Med. 1917;20:840. [Crossref]

15. Pensky J, Levy LR, Lepow ICH. Partial purification of a serum inhibitor of C'1-esterase. J Biol Chem. 1961;236:1674-1679. [Crossref]
16. Landerman N. Hereditary angioeneurotic edema: I. Case reports and review of the literature. J Allergy. 1962;33:316-329. [Crossref]

17. Donaldson VH, Evans RR. A biochemical abnormality in hereditary angioneurotic edema: absence of serum inhibitor of C'1-esterase. Am J Med. 1963;35:37-44. [Crossref]

18. Donaldson VH, Rosen FS. Action of complement in hereditary angioneurotic edema: the role of C'1-esterase. J Clin Invest. 1964;43(11):2204-2213. [Crossref]

19. Rosen FS, Pensky J, Donaldson V, Charache P. Hereditary angioneurotic edema: two genetic variants. Science. 1965;148(3672):957-958. [Crossref]

20. Schapira M, Silver LD, Scott CF, et al. Prekallikrein activation and high-molecular-weight kininogen consumption in hereditary angioedema. $N$ Engl $\mathrm{J} \mathrm{Med}$. 1983;308(18):1050-1053. [Crossref]

21. Dunn JT, Silverberg M, Kaplan AP. The cleavage and formation of activated human Hageman factor by autodigestion and by kallikrein. J Biol Chem. 1982;257:1779-84. [Crossref]

22. Bock SC, Skriver K, Nielsen E, et al. Human C1 inhibitor: primary structure, cDNA cloning, and chromosomal localization. Biochemistry. 1986;25(15):4292-4301. [Crossref]

23. Theriault A, Whaley K, McPhaden AR, Boyd E, Connor JM. Regional assignment of the human C1-inhibitor gene to 11q11-q13.1. Hum Genet. 1990;84(5):477-479. [Crossref]

24. Nussberger J, Cugno M, Amstutz C, Cicardi M, Pellacani A, Agostoni A. Plasma bradykinin in angio-oedema. Lancet. 1998; 351:1693-7. [Crossref]

25. Caldwell JR, Ruddy S, Schur PH, Austen KF. Acquired C1 inhibitor deficiency in lymphosarcoma. Clin Immunol Immunopathol. 1972;1:39-52. [Crossref]

26. Gülbahar O. Angioedema without wheals: A clinical update. Balkan Med J. 2021;38(2): 73-81.

27. López Lera A. Pathophysiology and underlying mechanisms in hereditary angioedema. Balkan Med J. 2021;38(2): 82-88.

28. Valerieva A, Nedeva D, Yordanova V, Elena Petkova E, Staevska M. Therapeutic management of hereditary angioedema: past, present, and future. Balkan Med J. 2021;38(2): 89-103.

29. Bork K, Barnstedt SE, Koch P, Traupe H. Hereditary angioedema with normal C1-inhibitor activity in women. Lancet 2000;356(9225):213-217. [Crossref]

30. Binkley KE, Davis 3rd A. Clinical, biochemical, and genetic characterization of a novel estrogen-dependent inherited form of angioedema. J Allergy Clin Immunol. 2000;106(3):546-550. [Crossref]

31. Dewald G, Bork K. Missense mutations in the coagulation factor XII (Hageman factor) gene in hereditary angioedema with normal $\mathrm{C} 1$ inhibitor. Biochem Biophys Res Commun. 2006;343(4):1286-1289. [Crossref]

32. Magerl M, Germenis AE, Maas C, Maurer M. Hereditary angioedema with normal C1 Inhibitor: Update on evaluation and treatment. Immunol Allergy Clin North Am. 2017;37(3):571-584. [Crossref]

33. Germenis AE, Rijavec M, Veronez CL. Leveraging genetics for hereditary angioedema: A road map to precision medicine. Clin Rev Allergy Immunol. 2021 Jan 28. doi: 10.1007/s12016-021-08836-7. [Crossref]

34. Loules G, Parsopoulou F, Zamanakou M, et al. Deciphering the genetics of primary angioedema with normal levels of C1 inhibitor. J Clin Med. 2020;9(11):3402 [Crossref]

35. Germenis AE, Cicardi M. Driving towards Precision Medicine for angioedema without wheals. J Autoimmun. 2019;104:102312. [Crossref]

36. Wu MA, Bova M, Berra $\mathrm{S}$, et al. The central role of endothelium in hereditary angioedema due to C1 inhibitor deficiency. Int Immunopharmacol. 2020;82:106304. [Crossref]

37. Ponard D, Gaboriaud C, Charignon D, et al. SERPING1 mutation update: Mutation spectrum and C1 Inhibitor phenotypes. Hum Mutat. 2020;41(1):38-57. [Crossref]

38. Vatsiou S, Zamanakou M, Loules G, et al. A novel deep intronic SERPING1 variant as a cause of hereditary angioedema due to C1-inhibitor deficiency. Allergol Int. 2020; 69(3):443-449. [Crossref]

39. Hujová P, Souček P, Grodecká L, et al. Deep intronic mutation in SERPING1 caused hereditary angioedema through pseudoexon activation. J Clin Immunol. 2020; 40(3):435-446. [Crossref]

40. Cicardi M, Igarashi T, Rosen FS, Davis AE 3rd. Molecular basis for the deficiency of complement 1 inhibitor in type I hereditary angioneurotic edema. J Clin Invest 1987;79(3):698-702. [Crossref]

41. Haslund D, Ryø LB, Majidi SS, et al. Dominant-negative SERPING1 variants cause intracellular retention of $\mathrm{C} 1$ inhibitor in hereditary angioedema. $J$ Clin Invest. 2019;129(1):388-405. [Crossref] 
42. Suffritti C, Zanichelli A, Maggioni L, Bonanni E, Cugno M, Cicardi M. High-molecular-weight kininogen cleavage correlates with disease states in the bradykinin-mediated angioedema due to hereditary C1-inhibitor deficiency. Clin Exp Allergy. 2014;44(12):1503-1514. [Crossref]

43. Charignon D, Ghannam A, Ponard D, Drouet C. Hereditary C1 inhibitor deficiency is associated with high spontaneous amidase activity. Mol Immunol. 2017;85:120-122. [Crossref]

44. Lara-Marquez ML, Christiansen SC, Riedl MA, Herschbach J, Zuraw BL. Threshold-stimulated kallikrein activity distinguishes bradykinin- from histamine-mediated angioedema. Clin Exp Allergy. 2018;48(11):1429-1438. [Crossref]

45. Larrauri B, Hester CG, Jiang H, et al. sgp120 and the contact system in hereditary angioedema: A diagnostic tool in HAE with normal $\mathrm{C} 1$ inhibitor. Mol Immunol. 2020;119:27-34 [Crossref]

46. Kaplan AP, Maas C. The search for biomarkers in hereditary angioedema. Front Med. 2017;4:206. [Crossref]

47. Nicola S, Rolla G, Brussino L. Breakthroughs in hereditary angioedema management: a systematic review of approved drugs and those under research. Drugs Context. 2019;8:212605.[Crossref]

48. Bygum A, Aygören-Pürsün E, Beusterien K, et al. Burden of illness in hereditary angioedema: A conceptual model. Acta Derm Venereol. 2015;95(6):706-710. [Crossref]

49. Bork K, Davis-Lorton M. Overview of hereditary angioedema caused by C1-inhibitor deficiency: assessment and clinical management. Eur Ann Allergy Clin Immunol. 2013;45:7-16.

50. Busse PJ, Christiansen SC. Hereditary angioedema. NEngl JMed. 2020;382(12):11361148. [Crossref]

51. Speletas M, Szilagyi A, Psarros F, et al. Hereditary angioedema: molecular and clinical differences among European populations. J Allergy Clin Immunol. 2015;135(2):570573. [Crossref]

52. Caccia S, Suffritti $C$, Carzaniga $T$, et al. Intermittent $\mathrm{C} 1$-inhibitor deficiency associated with recessive inheritance: Functional and structural insight. Sci Rep. 2018;8(1):977. [Crossref]

53. Margaglione M, D'Apolito M, Santocroce R, Maffione AB. Hereditary angioedema: Looking for bradykinin production and triggers of vascular permeability. Clin Exp Allergy. 2019;49(11):1395-1402. [Crossref]

54. Speletas M, Szilágyi A, Csuka D, et al. F12-46C/T polymorphism as modifier of the clinical phenotype of hereditary angioedema, Allergy. 2015;70(12):1661-1664. [Crossref]

55. Gianni P, Loules G, Zamanakou M, et al. Genetic determinants of the C1-INH deficiency angioedema (C1-INH-HAE) age of onset. Int J Allergy Immunol 2017;174(34):200-204. [Crossref]

56. Rijavec M, Košnik M, Andrejević S, Karadža-Lapić L, Grivčeva-Panovska V, Korošec $\mathrm{P}$. The functional promoter F12-46C/T variant predicts the asymptomatic phenotype of C1-INH-HAE. Clin Exp Allergy. 2019;49(11):1520-1522. [Crossref]

57. Iwaki T, Castellino F. Plasma levels of bradykinin are suppressed in factor XII-deficient mice. Thromb Haemost 2006;95(6):1003-1010. [Crossref]

58. Shariat-Madar Z, Mahdi F, Schmaier AH. Identification and characterization of prolylcarboxypeptidase as an endothelial cell prekallikrein activator. $J$ Biol Chem. 2002;277(20):17962-17969. [Crossref]
59. Joseph K, Tholanikunnel BG, Kaplan AP. Heat shock protein 90 catalyzes activation of the prekallikrein-kininogen complex in the absence of factor XII. Proc Natl Acad Sci U S A. 2002;99(2):896-900. [Crossref]

60. Drouet C, Désormeaux A, Robillard J, et al. Metallopeptidase activities in hereditary angioedema: effect of androgen prophylaxis on plasma aminopeptidase P. J Allergy Clin Immunol. 2008;121(2):429-433. [Crossref]

61. De Maat S, Hofman ZLM, Maas C. Hereditary angioedema: the plasma contact system out of control. J Thromb Haemost. 2018;16(9):1674-1685. [Crossref]

62. Han ED, MacFarlane RC, Mulligan AN, Scafidi J, Davis AE 3rd. Increased vascular permeability in $\mathrm{C} 1$ inhibitor-deficient mice mediated by the bradykinin type 2 receptor. J Clin Invest. 2002;109:1057-63. [Crossref]

63. Kishimoto TK, Viswanathan K, Ganguly T, et al. Contaminated heparin associated with adverse clinical events and activation of the contact system. $N$ Engl J Med. 2008;358:2457-2467.

64. Adam A, Montpas N, Keire D, et al. Bradykinin forming capacity of oversulfated chondroitin sulfate contaminated heparin in vitro. Biomaterials. 2010;31(22):57415748. [Crossref]

65. Zhou ZH, Chen T, Arora K, Hyams K, Kozlowski S. Complement C1 esterase inhibitor levels linked to infections and contaminated heparin-associated adverse events. PLoS One. 2012;7(4):e34978. [Crossref]

66. Hofman ZLM, Relan A, Zeerleder S, Drouet C, Zuraw B, Hack CE. Angioedema attacks in patients with hereditary angioedema: Local manifestations of a systemic activation process. J Allergy Clin Immunol. 2016;138(2):359-366. [Crossref]

67. Hofman ZLM, Relan A, Hack CE. Hereditary Angioedema attacks: local swelling at multiple sites. Clin Rev Allergy Immunol. 2016;50(1):34-40. [Crossref]

68. Prematta MJ, Kemp JG, Gibbs JG, Mende C, Rhoads C, Craig TJ. Frequency, timing, and type of prodromal symptoms associated with hereditary angioedema attacks. $\mathrm{Al}$ lergy Asthma Proc. 2009;30(5):506-511. [Crossref]

69. Magerl M, Doumoulakis G, Kalkounou I, et al. Characterization of prodromal symptoms in a large population of patients with hereditary angio-oedema. Clin Exp Dermatol. 2014;39(3):298-303. [Crossref]

70. Ghebrehiwet B, Geisbrecht BV, Xu X, Savitt AG, Peerschke EIB. The C1q Receptors: Focus on gC1qR/p33 (C1qBP, p32, HABP-1). Semin Immunol. 2019;45:101338. [Crossref]

71. Taylor SL, Wahl-Jensen V, Copeland AM, Jahrling PB, Schmaljohn CS. Endothelial cell permeability during hantavirus infection involves factor XII-dependent increased activation of the kallikrein kinin system. PLoS Pathog. 2013; 9(7):e1003470. [Crossref]

72. Gershom ES, Sutherland MR, Lollar P, Pryzdial EL. Involvement of the contact phase and intrinsic pathway in herpes simplex virus-initiated plasma coagulation. $J$ Thromb Haemost. 2010;8(5):1037-1043. [Crossref]

73. Loffredo S, Bova M, Suffritti C, et al. Elevated plasma levels of vascular permeability factors in C1 inhibitor-deficient hereditary angioedema. Allergy. 2016;71(7):989-996. [Crossref]

74. Bova M, Suffritti C, Bafunno V, et al. Impaired control of the contact system in hereditary angioedema with normal C1-inhibitor. Allergy. 2020;75(6):1394-1403. [Crossref] 